\title{
The Immature Rat Small Intestine Exhibits an Increased Sensitivity and Response to Escherichia coli Heat-Stable Enterotoxin
}

\author{
MITCHELL B. COHEN, M. SUSAN MOYER, MARCIA LUTTRELL, AND RALPH A. GIANNELLA \\ Division of Gastroenterology and Nutrition, Children's Hospital Research Foundation, Division of Digestive \\ Diseases, University of Cincinnati College of Medicine, and VA Medical Center, Cincinnati, Ohio 45229
}

\begin{abstract}
Escherichia coli which elaborate heat stable enterotoxin (ST) are a major cause of endemic diarrhea in infants. The reason(s) for this increased susceptibility of infants to ST-mediated diarrhea is unknown. We investigated the possibility that the immature (14 and 21 day old) rat small intestine is more sensitive to $\mathrm{ST}$ than is the adult. Initially we found there was a 600 -fold increased jejunal sensitivity to $\mathrm{ST}$ in the immature animals as measured by dose required for half maximal secretion. Also there was a greater jejunal secretory response in the immature animals (14 $\geq 21$ days old $>$ adult). To determine the cause for this increased sensitivity and secretory response to $S T$, we examined: 1) binding characteristics of ${ }^{125} \mathrm{I}-\mathrm{ST}$ to brush border membrane (BBM) receptors and 2) membrane bound guanylate cyclase activation by ST in both immature and adult rats. Our findings demonstrate that more ST receptors are present in jejunal BBM from 14- and 21-dayold rats than in jejunal BBM from adult rats $(2.34 \pm 0.18$, $2.85 \pm 0.82$, and $0.79 \pm 0.13 \times 10^{12}$ receptors $/ \mathrm{mg} \mathrm{BBM}$ protein, respectively), while the affinity of the $B B M$ receptor for ST is similar at all three ages in both jejunum and ileum. Furthermore, both the jejunum and ileum of the rats of all three ages revealed an equal sensitivity of guanylate cyclase to activation by ST. These findings suggest that the increased number of jejunal receptors in the immature rat may, in part, explain the increased sensitivity and secretory response observed in vivo. (Pediatr Res 20:555$560,1986)$
\end{abstract}

\section{Abbreviations}

ST, Escherichia coli heat-stable enterotoxin BBM, brush border membranes

$\mathrm{ED}_{50}$, dose required for half maximal response

$K_{2}$, association constant

ETEC, enterotoxigenic $E$. coli

In underdeveloped countries, diarrheal disease is the cause of up to $50 \%$ of infant mortality (1-4). Bacterial diarrhea also is associated with malnutrition and growth retardation $(1,5)$. Infection with ETEC is the most common cause of this endemic diarrhea $(2,6-8)$ and ST the most common toxin elaborated by

Received October 21, 1985; accepted February 4, 1986

Correspondence and reprint requests to Ralph A. Giannella, M.D., Professor of Medicine and Director, Division of Digestive Diseases, Department of Medicine, University of Cincinnati College of Medicine, ML 595, 231 Bethesda Avenue, Cincinnati, OH 45267.

Supported in part by United Order True Sisters, Ruth Lodge 18 Fellow Training Grant, VA Research Grant 539-3108-01, and Public Health Service Grant AI 20261, National Institute of Allergy and Infectious Diseases
ETEC $(1,5)$. The mechanism(s) for the increased susceptibility of infants to toxigenic diarrhea is unknown, but may be related to a) increased exposure to ETEC in weaning foods, b) impaired host immunity to infection, and/or c) increased sensitivity to the elaborated toxin.

Escherichia coli heat stable enterotoxins are a family of peptides, containing either 18 or 19 amino acids and sharing 13 common amino acids in the carboxyl terminal portion of the molecule, which is the region of the active site (9-12). After binding to its enterocyte receptor (13), ST exerts a secretory effect by decreasing the coupled influx of sodium and chloride and stimulating the active secretion of chloride $(14,15)$. These effects are mediated by the guanylate cyclase-cGMP system $(14,16,17)$.

The purpose of the present study was to determine whether the immature small intestine was more sensitive to ST and if so, to elucidate the mechanisms of this increased sensitivity. To do this we compared: a) the binding of ${ }^{125} \mathrm{I}-\mathrm{ST}$ to enterocyte receptors and b) the magnitude of receptor-effector coupling of ST, i.e. the degree of guanylate cyclase activation per unit of receptor occupied, in both immature and adult rats. Our findings demonstrate that the immature ( 14 and 21 day old) rat small intestine is more sensitive to ST than the adult and that an increased number of jejunal enterocyte receptors may, in part, account for this increased sensitivity.

\section{MATERIALS AND METHODS}

ST from $E$. coli strain $18 \mathrm{D}$ was purified as previously described (18). Pure ST was radioiodinated by a lactoperoxidase method (19) and purified by a high-performance liquid chromatography technique which separates monoiodinated ST of high specific activity $(1240 \mathrm{Ci} / \mathrm{mmol})$ and a biologic activity equal to that of native ST (10).

Animals. Fourteen- and 21-day-old rats (10-12 pups/litter) with their dams, and adult male Sprague-Dawley rats were obtained from Harlan Laboratories (Indianapolis, IN), 1-7 days prior to study. They were housed in a temperature controlled room at $22^{\circ} \mathrm{C}$ with alternating $12 \mathrm{~h}$ light-dark cycles. Adult rats were allowed Purina Rat Chow (St. Louis, MO) and water ad libitum; 14-day-old rats were suckled by their dams and 21-dayold rats were both suckled and allowed Chow. Animals were sacrificed by cervical dislocation.

Chemicals. ${ }^{125} \mathrm{I}-\mathrm{Na}(>350 \mathrm{mCi} / \mathrm{ml})$ was obtained from Amersham (Arlington Heights, IL) Phenylmethylsulfonyl fluoride, HEPES, and enzymatic substrates were obtained from Sigma Chemical (St. Louis, MO). All other chemicals were of reagent grade.

Studies of in vivo intestinal secretion. In vivo intestinal secretory response to pure ST was studied in nonfasted 14-day-old, 21-day-old, and adult rats. After intraperitoneal thiopental anesthesia, the abdomen was opened, the small intestine was rinsed 
with normal saline and divided by surgical ligatures into three noncontiguous $10 \mathrm{~cm}$ loops (jejunum, midileum, distal ileum). An injection of pure ST (0.01-5000 ng/loop) was made with a $30 \mathrm{G}$ needle in a volume of modified Dulbecco's medium (128 $\mathrm{mM} \mathrm{NaCl}, 2.7 \mathrm{mM} \mathrm{KCl}, 8 \mathrm{mM} \mathrm{Na} \mathrm{HPO}_{4}$, and $1.2 \mathrm{mM} \mathrm{MgSO}_{4}$, $\mathrm{pH} 7.1$ ), chosen to cause minimal distention (14 days: $200 \mu \mathrm{l}, 21$ days: $500 \mu \mathrm{l}$, adult: $1000 \mu \mathrm{l})$. In each animal a control loop injection of Dulbecco's medium was made. Thus, each animal had two doses of ST and a control loop. The position of the test and control loops was varied to allow at least three determinations per dose at each site. The abdomen was closed and the animal placed in a plexiglass housing. A Proportional Electronic Temperature Controller (Cole Parmer, Chicago, IL) was attached to a probe to maintain rectal temperature at $38-39^{\circ} \mathrm{C}$. After a 3 -hr incubation, the abdomen was reopened, the ligated loops were removed, and weighed intact. Loops were opened and milked dry of accumulated fluid. Net secretion was calculated as the volume of fluid in a test loop, minus the fluid in a control loop at a comparable site, and expressed as $\mathrm{ml} / \mathrm{g}$ intestinal weight. Expressing the data a $\mathrm{ml} / \mathrm{cm}$ intestinal length did not alter the results. From these data a dose response curve was constructed and the dose required for $\mathrm{ED}_{50}$ was calculated using the computer program "Allfit" (20), as modified by Teicher (21).

$B B M$. BBM were prepared using a modification of the divalent cation precipitation technique described by Schmitz et al. (22). Small intestine from four adult rats or two litters of rat pups was divided into equal thirds (proximal, middle, distal), inverted, and scraped with a glass slide. The mucosal scrapings were diluted $30: 1$ in ice-cold homogenizing solution $(50 \mathrm{mM}$ mannitol-2 $\mathrm{mM}$ Tris, $\mathrm{pH} 7.1-0.1 \mathrm{mM}$ phenylmethylsulfonyl fluoride) and homogenized for 2 min on speed setting no. 10 in a Sorvall Omni Mixer (Dupont Instruments, Wilmington, DE). All subsequent steps were carried out at $4^{\circ} \mathrm{C}$. The homogenate was brought to a concentration of $10 \mathrm{mM} \mathrm{CaCl}_{2}$, by addition of $1 \mathrm{M}$ $\mathrm{CaCl}_{2}$, mixed for $15 \mathrm{~min}$, and spun at $2000 \times g$ in a Sorvall RC5-B Superspeed Centrifuge for $10 \mathrm{~min}$. The pellet containing nuclei and mitochondria was discarded and the supernatant was spun at $17,500 \times g$ for $20 \mathrm{~min}$. To remove basolateral membrane and endoplasmic reticulum, this pellet was twice washed in ice cold buffer B ( $300 \mathrm{mM}$ mannitol-16 mM Hepes-10 mM Tris, pH 7.1) containing $10 \mathrm{mM} \mathrm{MgCl}$. Each wash consisted of a 15min mixing period, a 10 -min spin at $2000 \times g$, and a 20 -min spin of this supernatant at $17,500 \times g$. These $\mathrm{MgCl}_{2}$ washes provided a $50 \pm 10 \%$ further enrichment in lactase and a $43 \pm$ $10 \%$ further enrichment in sucrase activity. The resulting final pellet was resuspended in $30 \mathrm{ml}$ of Buffer B and homogenized with 10 slow up-down strokes of a glass-Teflon homogenizer. This membrane suspension was spun at $19,000 \times g$ for $30 \mathrm{~min}$, and the pellet was washed in modified Dulbecco's medium and spun at $19,000 \times g$ for 30 min prior to use in binding experiments.

Validation of the preparation was accomplished by documenting a) $>90 \%$ recovery of all marker enzymes and of protein, b) comparable sucrase (23) or lactase (24) enrichment (19.7 \pm $1.1-, 17.1 \pm 1.3-$, and 15.0 \pm 1.0 -fold for adult, 21-day-old, and 14-day-old rats, respectively), c) lack of enrichment of $\mathrm{Na}^{+}-\mathrm{K}^{+}$ ATPase $(25,26)$, and deenrichment of NADPH cytochrome C reductase (27) and succinic acid cytochrome $C$ reductase $(28)$ (enzymatic markers for basolateral membrane, endoplasmic reticulum, and mitochondria, respectively). Protein was measured by the method of Lowry et al. (29) using bovine serum albumin (Sigma) as the standard.

Binding of ST to BBM. A competitive inhibition binding assay was used, as previously described (13), to determine binding of ST to BBM. Briefly, BBM $(40-100 \mu \mathrm{g})$ were incubated with a constant amount of ${ }^{125} \mathrm{I}-\mathrm{ST}$ in $12 \times 75$ glass tubes containing various concentrations of cold ST $(0.5$ to $1000 \mathrm{ng} / \mathrm{ml}), 0.15 \%$ bovine serum albumin, and modified Dulbecco's medium in a total volume of $1 \mathrm{ml}$. The incubation was terminated after 30 min at $25^{\circ} \mathrm{C}$, by rapid suction filtration using a Millipore multichamber sampling manifold (Millipore Corp., Boston, MA) and Whatman GF/B glass fiber filters (Whatman Ltd., Maidstone, England). Filters were then rinsed twice with $5 \mathrm{ml}$ of icecold Dulbecco's solution, inserted into glass test tubes, and counted in a Packard $\gamma$-scintillation spectrometer (Downers Grove, IL). These counts represent total bound ${ }^{125} \mathrm{I}-\mathrm{ST}$. Specific binding was determined by subtracting nonspecific binding $(\leq 5 \%)$, i.e. the amount of ${ }^{125} \mathrm{I}-\mathrm{ST}$ bound in the presence of 505 nM unlabeled ST. Background $(\leq 2 \%)$, i.e. percentage of radioactivity added which bound to filters in the absence of BBM, was also subtracted from total bound. $\mathrm{K}_{\mathrm{a}}$ and number of $5 \mathrm{~T}$ receptors were calculated using the least squares fit computer program, "Ligand" as described by Munson and Rodbard (30) and modified by Teicher (31) for use on the Apple IIe computer (Cupertino, CA).

Activation of guanylate cyclase. After sacrifice, the same procedure utilized to prepare BBM, was followed through homogenization. The homogenate was diluted 30 -fold in ice cold dithiothreitol buffer $(0.25 \mathrm{M}$ sucrose- $50 \mathrm{mM}$ Tris $\mathrm{HCl}$, pH $7.9-$ $1.0 \mathrm{mM}$ EDTA-1.0 mM dithiothreitol). A pellet was obtained by centrifugation at $10,000 \times g$ for 20 min on a Beckman L8-70 ultracentrifuge (Palo Alto, CA). This pellet was washed in $5 \mathrm{mM}$ Tris, $\mathrm{pH} 7.6$, and resuspended to approximately $10-20 \mu \mathrm{g}$ protein $/ 10 \mu \mathrm{l}$. Basal- and ST-stimulated guanylate cyclase activation was measured as described by Waldman et al. (32). Cyclic GMP was measured by radioimmunoassay as previously published (16). ST-stimulated guanylate cyclase activities, measured in pmol cGMP generated $* \min ^{-1} * \mathrm{mg}_{\text {protein }}{ }^{-1}$, are expressed as fold increase over basal levels. Various doses of pure ST were used to construct a dose response curve and an $\mathrm{ED}_{50}$ was calculated using the "Allfit" computer program (21).

Data presentation and analysis. For in vivo experiments, each point was determined in triplicate; for in vitro experiments, each point was determined in duplicate, and experiments repeated in triplicate. All data are presented as mean \pm SEM. The data were evaluated statistically by ANOVA. Subsequent paired comparisons were performed using the Bonferroni correction of the Student's $t$-test.

\section{RESULTS}

\section{Studies of in Vivo Intestinal Secretion.}

Jejunum. The secretory responses of ligated jejunal loops to various doses of pure ST are shown in Figure 1. In the 14- and 21-day-old animals there was increased secretion with increasing doses of ST, when net secretion was measured after a 3-h incubation. This was in contrast to a flat dose response curve observed in the adult jejunum over the dose range tested. As also shown in Figure 1, over a broad dose range, the secretory response of the 14- and 21-day-old animals was greater than that seen in the adults. Since the volume of the intraluminal injection of toxin was adjusted for age, secretion could be expressed as a variable of ST concentration (as is done in Figs. 1 and 2 and Table 1) or as a variable of total dose administered (ng/loop). Expressing the data by either method gave similar results. At the maximum dose tested $(5000 \mathrm{ng} / \mathrm{loop})$, jejunal secretion was significantly greater in the 14- and 21-day-old animals than in the adult rats $(1.86 \pm 0.74$ and $1.49 \pm 0.44$, versus $0.07 \pm 0.07$ $\mathrm{ml} / \mathrm{g}$ intestine, respectively, $p<0.001$ ).

As shown in Figure 1 and Table 1, the jejunum of the 14-dayold rat was significantly more sensitive to ST than that of the 21day-old rat. When expressed as $\mathrm{ED}_{50}$ (the dose of ST inducing $50 \%$ of maximal secretion), there was 600 -fold increased sensitivity to ST, i.e. $3.74 \pm 2.56$ versus $2400 \pm 1161 \mathrm{ng} / \mathrm{ml}$, respectively, $p<0.005$. Both the 14- and 21-day-old jejunum were more sensitive than the adult jejunum which demonstrated insignificant secretion (Fig. 1 and Table 1).

Ileum. The ileum demonstrated a different pattern of response and sensitivity to ST than did the jejunum (Fig. 2). In the ileum, 


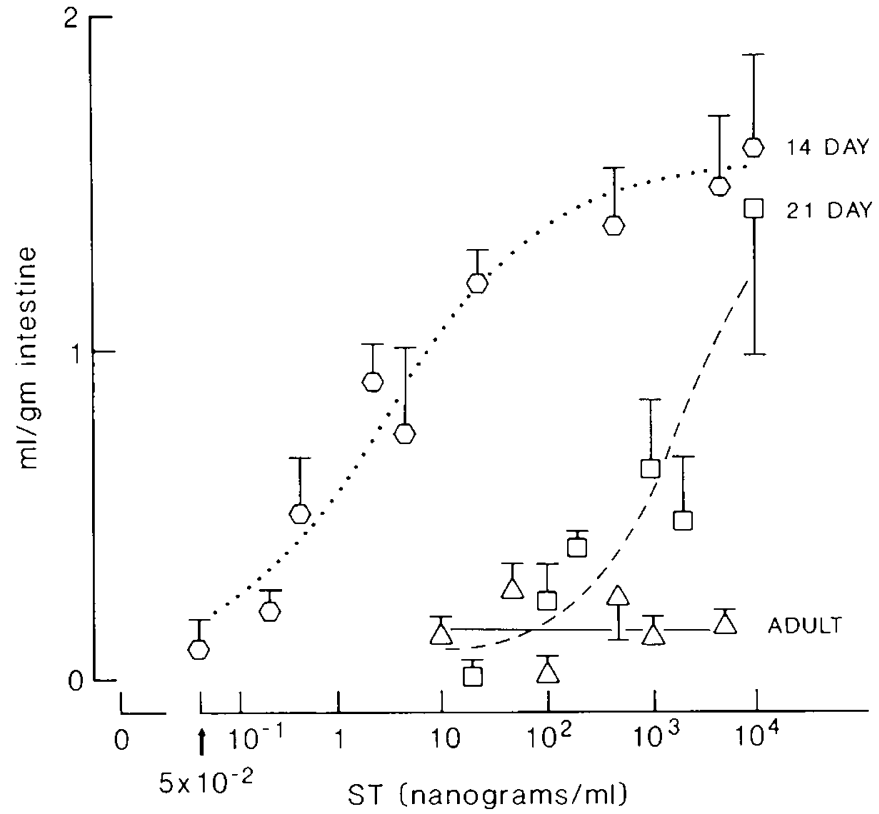

Fig. 1. Effect of various doses of ST on in vivo jejunal secretion in 14-day-old, 21-day-old, and adult rats. Increasing doses of pure ST were injected into in vivo ligated jejunal loops in 14-day-old, 21-day-old, and adult animals and secretion measured $3 \mathrm{~h}$ later. Secretion is expressed as $\mathrm{ml} / \mathrm{g}$ of intestine and each point is the mean \pm SEM of at least three loops.

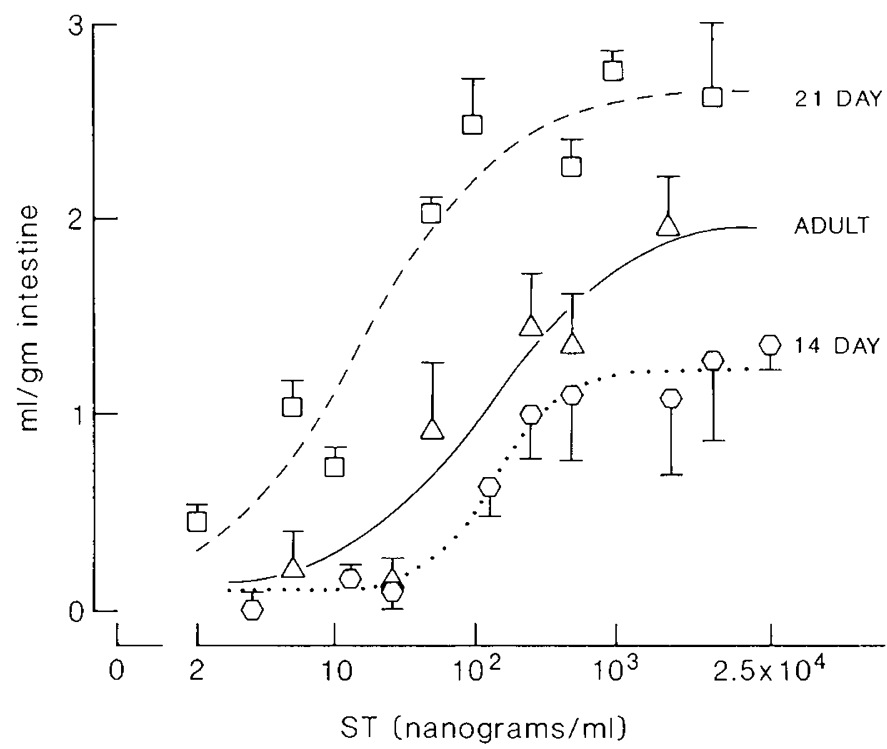

Fig. 2. Effect of various doses of ST on in vivo ileal secretion in 14day-old, 21-day-old, and adult rats (see legend Fig. 1).

Table 1. Dose $(\mathrm{ng} / \mathrm{ml})$ of $S T$ required for $50 \%$ maximal secretion $\left(E D_{50}\right)$ in ligated jejunal and ileal loops of various age rats

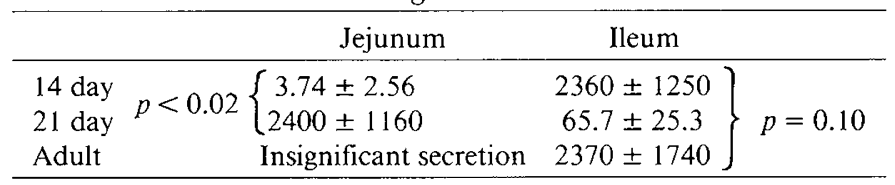

all three age groups demonstrated increasing secretion with increasing dose of ST. Over a broad dose range, the secretory response of the 21-day-old animals was greater than the adult and 14-day-old animals. Furthermore, at the maximum dose tested (5000 ng/loop), ileal secretion was similar in the adult and 21-day-old animals, and both were greater than the 14-day-old animals $(2.75 \pm 0.80$ and $3.37 \pm 0.56$, versus $1.34 \pm 0.13$, respectively, $p<0.05$ ).

Although at the higher ST doses, the absolute secretory response of the 14-day-old ileum was less than that in the older animals (Fig. 2); the sensitivity to ST of the 14-day-old ileum was similar to the adult rats (Table 1). The 21-day-old ileum appeared to be more sensitive to ST than the younger or older animals $(65.7 \pm 25.3$ versus $2362 \pm 1248$ and $2366 \pm 1737 \mathrm{ng} /$ $\mathrm{ml}$, respectively) but these $\mathrm{ED}_{50}$ values were not statistically different from each other when evaluated by ANOVA.

Jejunum versus ileum. At the maximum dose tested (5000 ng/ loop), the jejunal response was half of the ileal response in the 21 -day-old animals $(1.49 \pm 0.44$ versus $3.37 \pm 0.56 \mathrm{ml} / \mathrm{g}$, respectively, $p<0.05)$, and $<3 \%$ of the ileal response in the adult animals $(0.07 \pm 0.07$ versus $2.75 \pm 0.80$, respectively, $p<0.003)$. In contrast, the jejunum and ileum of the 14-day-old rat demonstrated a similar maximal secretory response $(1.86 \pm 0.74$ versus $1.34 \pm 0.13 \mathrm{ml} / \mathrm{g}$, respectively).

The 14-day-old rat jejunum was also 600 -fold more sensitive to ST than the 14-day-old ileum (Table 1). In contrast, as measured by half maximal secretory response at $3 \mathrm{~h}$, the jejunum of both the 21-day-old and adult animals were significantly less sensitive to ST than the ileum in the same age animals.

Binding of ST to BBM. To determine whether differences in numbers of ST receptors or avidity of ST binding might explain the observed differences in sensitivity to ST, we determined the binding constant $\left(\mathrm{K}_{\mathrm{a}}\right)$ and number of receptors/mg BBM protein $\left(\mathrm{B}_{\max }\right)$ in BBM preparations for 14-day-old, 21-day-old, and adult rats. These parameters were determined by using a competitive inhibition binding assay, i.e. binding measured in the presence of a constant amount of ${ }^{125} \mathrm{I}-\mathrm{ST}$ and increasing quantities of unlabeled ST.

As shown in Figure 3, increasing doses of unlabeled ST progressively and identically inhibited the binding of ${ }^{125} \mathrm{I}-\mathrm{ST}$ to jejunal BBM of 14-day-old, 21-day-old, and adult rats. The competitive inhibition curves for the ileal BBM of the various

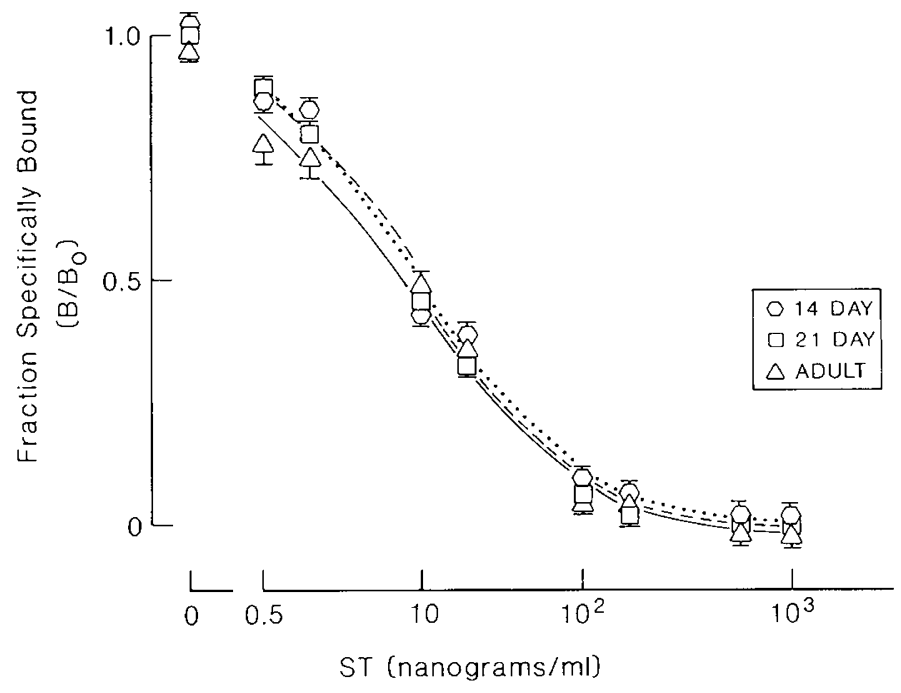

Fig. 3. Competitve inhibition of ${ }^{125} \mathrm{I}-\mathrm{ST}$ binding to BBM by increasing doses of native ST. Jejunal BBM from 14-day-old, 21-day-old, and adult animals were incubated with a constant amount of ${ }^{125} \mathrm{I}-\mathrm{ST}$ and increasing doses of cold ST at $25^{\circ} \mathrm{C}$ for $30 \mathrm{~min}$ in $1 \mathrm{ml}$ of Dulbecco/bovine serum albumin buffer. ${ }^{125}$ I-ST specific binding to BBM was determined as described in "Materials and methods" and binding is expressed as fraction of ${ }^{125} \mathrm{I}-\mathrm{ST}$ bound in the absence of added cold toxin. Each point is the mean \pm SEM of at least three experiments. 
aged rats were identical to those observed in the jejunum (data not shown).

When $\mathrm{ED}_{50}$ values for the dose of ST required to inhibit $50 \%$ of ST binding to jejunal and ileal BBM were calculated, they were the same in suckling, weanling, and adult animals, i.e. range $4.5 \pm 0.5$ to $5.2 \pm 0.6 \mathrm{ng} / \mathrm{ml}$. As suggested by these $E D_{50}$ values, and as shown in Table 2, when these data were analyzed with the "Ligand" computer program (30), the $\mathrm{K}_{\mathrm{a}}$ of ${ }^{125} \mathrm{I}-\mathrm{ST}$ binding to jejunal and ileal BBM was also similar at all three ages. However, 3- to 4-fold more ST receptors were present in jejunal BBM from 14- and 21-day-old rats than in jejunal BBM from adult rats $(2.34 \pm 0.18$ and $2.85 \pm 0.95$ versus $0.79 \pm 0.13 \times$ $10^{12}$ receptors/mg BBM protein, respectively), although only the former achieved statistical significance, $p<0.02$. The number of receptors/mg of ileal BBM did not differ among the three animal groups.

Guanylate Cyclase Activation. To determine if increased receptor-effector coupling played a role in the increased response and sensitivity to ST, we measured small intestinal guanylate cyclase activity in response to various doses of ST (1-500 ng) in 14-day-old, 21-day-old, and adult rats. In both the jejunum and ileum, basal guanylate cyclase activity (measured in the absence of ST) was similar at all three ages, i.e. $17.68 \pm 5.50$ pmol cGMP * $\min ^{-1} * \mathrm{mg}$ protein ${ }^{-1}$.

As shown in the dose response curves, Figures 4 and 5 , increasing quantities of ST progressively increased the activation of guanylate cyclase. The pattern of guanylate cyclase activation by ST, was similar in the jejunum and ileum with adult animals $\geq 21$ day animals and both generally greater than 14-day-old animals. However, in the adult and 21-day-old animals, the absolute increases in the jejunum at a given dose were generally twice those seen in the ileum. This was in contrast to the 14-dayold animals where absolute guanylate cyclase activation was equal in the jejunum and ileum.

As shown in Figure 4, maximal jejunal guanylate cyclase activity was greatest in the adult and 21-day-old animals and least in the 14-day-old animals $(7.29 \pm 1.77-$, and $6.59 \pm 0.36-$ versus $2.86 \pm 0.34$-fold increase over basal levels respectively, $p<0.05$ ). As shown in Figure 5, the pattern of maximal ileal guanylate cyclase activation was similar to the jejunum. However, there were no statistical differences in the ileum between the adult, 21-day-old, and 14-day-old animals (3.93 $\pm 0.40-, 3.63$ \pm 0.32 -, and $2.72 \pm 0.37$-fold increase over basal levels, respectively).

When the data shown in Figures 4 and 5 were analyzed with the computer program "Allfit" (21), the $\mathrm{ED}_{50}$ values for the dose of ST required to achieve $50 \%$ of maximal guanylate cyclase activation were similar in suckling, weanling and adult animals, i.e. range $5.6 \pm 3.7$ to $16 \pm 14 \mathrm{ng}$ of ST.

Table 2. Comparison of ST binding parameters of jejunal and ileal BBM of various age rats

\begin{tabular}{lccc}
\hline & \multicolumn{3}{c}{ Avidity of binding $\left(\mathrm{K}_{\mathrm{a}}\right)^{*} \dagger$} \\
\cline { 2 - 4 } & 14 Day & 21 Day & Adult \\
\hline Jejunum & $3.11 \pm 0.67 \times 10^{8}$ & $4.52 \pm 0.30 \times 10^{8}$ & $5.04 \pm 0.82 \times 10^{8}$ \\
Ileum & $5.95 \pm 1.08 \times 10^{8}$ & $3.74 \pm 0.89 \times 10^{8}$ & $5.54 \pm 0.75 \times 10^{8}$ \\
& \multicolumn{3}{c}{ No. of receptors $\ddagger$} \\
\cline { 2 - 2 }
\end{tabular}

Jejunum $2.34 \pm 0.18 \times 10^{12} \S 2.85 \pm 0.95 \times 10^{12} 0.79 \pm 0.13 \times 10^{12} \S$ lleum $1.66 \pm 0.23 \times 10^{12} \quad 3.51 \pm 0.84 \times 10^{12} \quad 1.72 \pm 0.46 \times 10^{12}$

* Liter/mol.

$\dagger$ NS by ANOVA.

$\ddagger$ Numbers of receptors/mg BBM protein.

$\S p<0.005$, number of receptors in 14 -day jejunum versus adult jejunum.

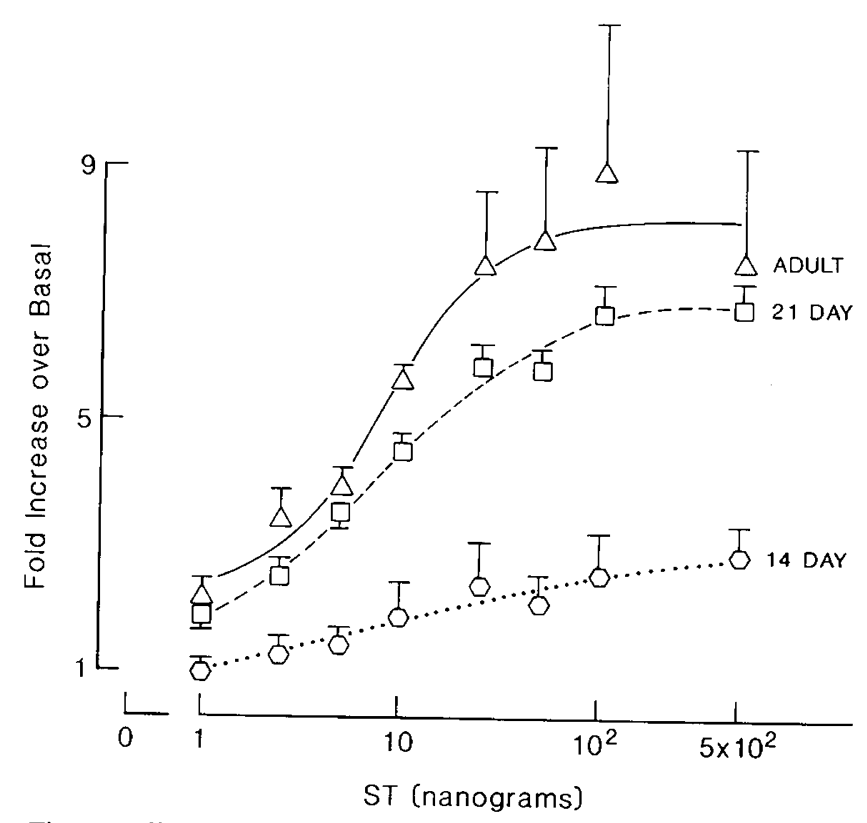

Fig. 4. Effects of various doses of ST on jejunal guanylate cyclase activity in 14-day-old, 21-day-old, and adult rats. Increasing doses of pure ST were incubated for $5 \mathrm{~min}$ with small intestinal membranes from 14-day-old, 21-day-old, and adult animals and guanylate cyclase activity measured as pmol cGMP * $\min ^{-1} * \mathrm{mg}$ protein ${ }^{-1}$ as described in "Materials and methods." Guanylate cyclase activity expressed as fold increase over basal levels. Each point is the mean \pm SEM of at least three experiments.

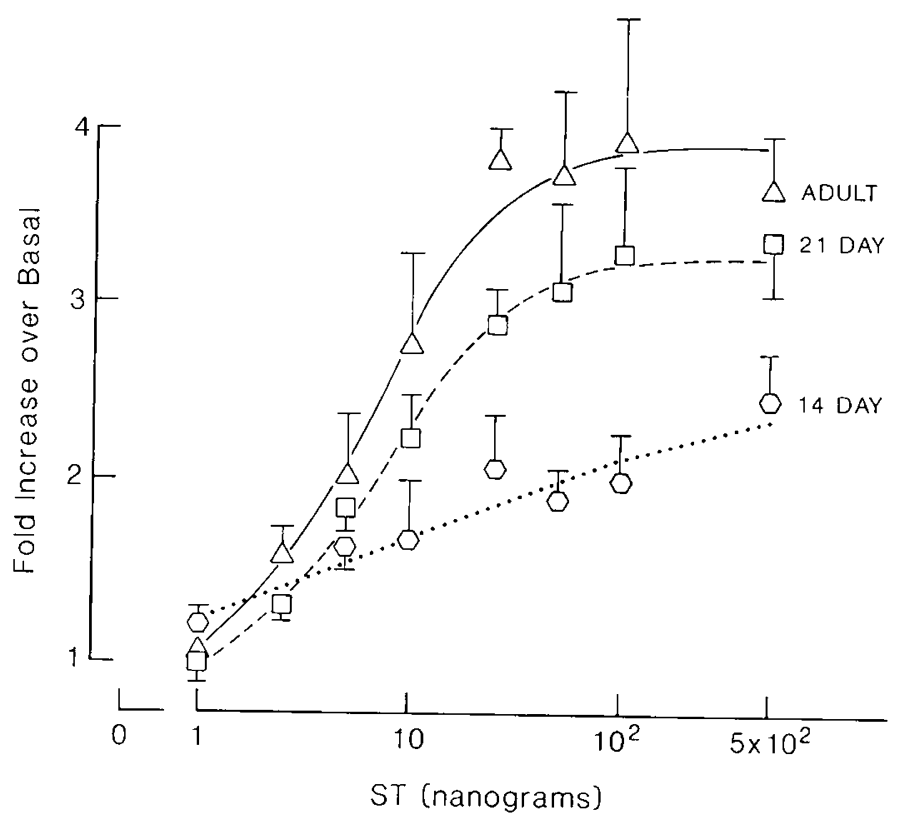

Fig. 5. Effects of various doses of ST on ileal guanylate cyclase activity in 14-day-old, 21-day-old, and adult rats (see legend Fig. 4).

\section{DISCUSSION}

Our data demonstrate that pure ST causes net secretion in the jejunum and ileum of immature (14 and 21 day old) rats as well as of adult rats. Jejunal secretion was greatest in the 14-day-old rats and least in the adult rats. Jejunal sensitivity to ST was also greatest in the 14-day-old animal.

In the ileum, there was increased ST-stimulated secretion in the 21-day-old animals, compared to adults. Despite an equal sensitivity to ST, the 14-day-old ileum demonstrated a diminished maximal secretory response compared with the older ani- 
mals. The explanation for this blunted response in the 14-dayold animals is unclear.

In both the 21-day-old and adult animals, and over a broad dose range, jejunal secretion was significantly less than the ileal response. Only in the 14-day-old animal did the jejunum participate equally with the ileum in the secretory response. If human infants demonstrate the same pattern, this phenomenon might explain the observed increased susceptibility of infants to STmediated diarrhea. Although increased exposure to enterotoxigenic bacteria and lack of protective antibodies may partly explain the increased frequency of diarrhea caused by ETEC in infants, our data directly demonstrate an increased sensitivity of the immature small intestine to ST.

To attempt to explain this increased sensitivity and response of the immature small intestine to ST, we examined the possibility that there were age-related differences in the avidity of the receptor for the toxin or in the number of ST receptors. Receptor occupancy has been postulated to be necessary for continued secretion (33); more avid binding might be associated with less spontaneous dissociation from the ST receptor and consequently more prolonged secretion for each ST molecule bound. Our findings, however, indicate that there were no significant differences in the avidity of binding $\left(\mathrm{K}_{\mathrm{a}}\right)$ of ST to receptors in the jejunum or ileum of the various age groups tested.

In contrast, more ST receptor sites were found in the jejunum of the 14- and 21-day-old rat compared with the jejunum of the adult rat, although only the former reached statistical significance. A greater number of ST binding sites in the developing animal, with an affinity for ST equal to that of the adult, may be a possible mechanism for an increase in jejunal sensitivity and response to ST in these younger animals.

We also investigated the possibility that increased receptoreffector coupling might explain the increased sensitivity to ST. After binding to the enterocyte receptor, ST activates the membrane bound guanylate cyclase-cGMP system $(13,14,16,17)$. If more guanylate cyclase molecules were activated in a younger animal for the same number of ST molecules bound, an increased sensitivity and response to ST would be observed.

As observed by other investigators (15), in the mature animal there was generally greater guanylate cyclase activity in the jejunum than in the ileum. However, the sensitivity $\left(\mathrm{ED}_{50}\right)$ of the guanylate cyclase-cGMP system to ST was similar at all three age groups in both the jejunum and the ileum. Furthermore, the increased sensitivity and response in ST-mediated secretion in the younger animals did not correspond to either an increased sensitivity or response to ST-mediated guanylate cyclase activation. In fact, the guanylate cyclase response of the 14-day-old animals was often less than that of the more mature animals. We did not measure cGMP accumulation in response to ST. It is possible that cGMP accumulation might be greater in the intestine of the younger animals due to decreased degradation of cGMP rather than increased activation of guanylate cyclase. It is also possible that novel secondary or tertiary intracellular messengers are involved in the secretory process in these younger animals and that guanylate cyclase activation represents only part of the pathway involved in secretion.

Of interest is that in the 14-day-old jejunum, the $\mathrm{ED}_{50}$ values for ST-induced secretion, binding of ST to BBM, and ST-induced activation of guanylate cyclase were all similar. In contrast, at all other sites and ages studied, the $\mathrm{ED}_{50}$ for ST-induced secretion was significantly greater than that for ST binding or activation of guanylate cyclase. However, since these sensitivities to ST were measured in three separate systems, the relationships of these parameters may not be directly comparable.

In summary, there is an increased sensitivity and response to ST-mediated small intestinal secretion in the developing rat. Furthermore, the role of the jejunum in the secretory response appears foremost in the developing rat. Analysis of the kinetics of binding of ST to its enterocyte receptor indicates that there are an increased number of equally avid receptors for ST in the jejunum of the 14-day-old rat compared with the jejunum of the adult rat. There does not appear to be a difference in the degree or sensitivity of guanylate cyclase activation by ST between the developing and adult rat. An increased number of ST receptors in the developing intestine may, in part, account for the increased secretory response in the immature animal. However, further studies are needed to clarify the intracellular events that occur after ST binding to examine the possibility of developmental differences in intracellular response to $\mathrm{ST}$.

\section{REFERENCES}

1. Black RE, Brown KH, Becker S, Yunus M 1982 Longitudinal studies of infectious diseases and physical growth in rural Bangladesh: I. Patterns of morbidity. Am J Epidemiol 115:305-314

2. Black RE, Merson MH, Rahman AS, Yunus M, Alim AR, Huq I, Yolken RH, Curlin GT 1980 A two year study of bacterial, viral and parasitic agents associated with diarrhea in rural Bangladesh. J Infect Dis 142:660-664

3. Chen LC, Rahman M, Sarder AM 1980 Epidemiology and causes of death among children in a rural area of Bangladesh. Int $J$ Epidemiol 9:25-33

4. Walsh JA, Warren KS 1979 Selective primary health care: an interim strategy for disease control in developing countries. N Engl J Med 30:967-974

5. Black RE, Brown KH, Becker S, Alim AR, Huq I 1982 Longitudinal studies of infectious diseases and physical growth in rural Bangladesh: II. Incidence of diarrhea and association with known pathogens. Am J Epidemiol 115:315-324

6. Donta ST, Wallace RB, Whipp SC, Olarte J 1977 Enterotoxigenic Escherichia coli and diarrheal disease in Mexican children. J Infect Dis 135:482-485

7. Guerrant RL, Moore RA, Kirshen PM, Sande MA 1975 Role of toxigenic and invasive bacteria in acute diarrhea of childhood. N Engl J Med 293:567-573

8. Levine MM, Caplan ES, Waterman D, Cash RA, Hornick RB, Snyder MJ 1977 Diarrhea caused by Escherichia coli that produce only heat-stable enterotoxin. Infect Immun 17:78-82

9. Aimoto S 1982 Amino-acid sequence of a heat stable enterotoxin produced by enterotoxigenic Escherichia coli. Eur J Biochem 129:257-263

10. Thompson MR, Luttrell M, Overmann G, Giannella RA 1985 Biological and immunological characteristics of ${ }^{125}[-E$. coli heat-stable enterotoxin species purified by HPLC. Anal Biochem 148:26-36

11. Ikemura $H$, Wantanabe $H$, Aimoto $S$, Shimonis $Y$, Hara S, Takeda $T$, Takeda $\mathrm{Y}$, Miwatani T 1984 Heat stable enterotoxin $\left(\mathrm{ST}_{h}\right)$ of human enterotoxigenic Escherichia coli (strain SK-1). Structure-activity relationship. Bull Chem Soc Jpn 57:2550-2556

12. Moseley SL, Hardy JW, Hug MI, Echeverria P, Falkow S 1983 Isolation and nucleotide sequence of a gene encoding a heat-stable enterotoxin of $E$. coli. Infect Immun 39:1 167-1 174

13. Giannella RA, Luttrell M and Thompson M 1983 Binding of Escherichia coli heat stable enterotoxin to receptors on rat intestinal cells. Am J Physiol 245:G492-498

14. Field M, Graf LH, Laird WJ, Smith PL 1978 Heat stable enterotoxin of Escherichia coli: in vitro effects of guanylate cyclase activity, cyclic GMP concentration and ion transport in small intestine. Proc Natl Acad Sci USA 75:2800-2804

15. Guandalini S, Rao MC, Smith P, Field M 1982 cGMP modulation of ileal ion transport: in vitro effects of Escherichia coli heat-stable enterotoxin. Am J Physiol 243:G36-G41

16. Giannella RA, Drake KW 1979 Effect of purified E. coli heat-stable enterotoxin on intestinal cyclic nucleotide metabolism and fluid secretion. Infect Immun 24:19-23

17. Guerrant RL, Hughes JM, Chang B, Robertson DC, Murad F 1980 Activation of intestinal guanylate cyclase by heat-stable enterotoxin of Escherichia coli: studies of tissue specificity, potential receptors and intermediates. I Infect Dis 142:220-228

18. Staples JS, Asher SE, Giannella RA 1980 Purification and characterization of heat-stable enterotoxin produced by a strain of $E$. coli pathogenic for man. J Biol Chem 255:4716-4721

19. Giannella RA, Drake KW, Luttrell M 1981 Development of a radioimmunoassay for Escherichia coli heat stable enterotoxin-comparison with the suckling mouse bioassay. Infect Immun 33:186-192

20. Delean A, Munson PJ, Rodbard J 1978 Simultaneous analysis of families of sigmoidal curves; application to bioassay, radioligand assay, and physiologic dose response curves. Am J Physiol 235:E97-102

21. Teicher MH 1982 Allfit dose-response analysis program written in applesoft basic. Med 40, Biomedical Computing Technology Information Center, Nashville, TN

22. Schmitz J, Preiser H, Maestracci D, Ghosh BK, Cerda JJ, Crane RK 1973 Purification of human intestinal brush border membrane. Biochem Biophys Acta 323:98-112

23. Dahlqvist A 1968 Assay of intestinal dissacharidases. Anal Biochem 22:99107

24. Koldovsky O, Asp NG, Dahlquist A 1969 A method for the separate assay of "neutral" and "acid" beta-galactosidase in homogenates of rat small intestinal "neutral" a

mucosa. Anal Biochem 27:409-418
25. Wilson FA, Treanor LL 1981 Studies of relationships among bile acid uptake, $\mathrm{Na}^{+}, \mathrm{K}^{+}$-ATPase, and $\mathrm{Na}^{+}$gradient in isolated cells from rat ileum. Gastroenterology 81:54-60 
26. Taussky HH, Shorr E 1953 A microcolorimetric method for the determination of inorganic phosphorus. J Biol Chem 202:675-685

27. Sottocasa GL, Kuylenstierna B. Ernster L, Bernstrand A 1967 An electrontransport system associated with the outer membrane of liver mitochondria. J Cell Biol 32:415-438

28. Wannagat F-J, Adler RD, Ockner RK 1978 Bile acid-induced increase in bile acid-independent flow and plasma membrane NaK-ATPase activity in rat liver. J Clin Invest 61:297-307

29. Lowry OH, Rosebrough NJ, Farr AL, Randall RJ 1951 Protein measurement with the Folin phenol reagent. J Biol Chem 193:265-275
30. Munson PJ, Rodbard D 1980 Ligand-a versatile computerized approach for characterization of ligand-binding systems. Anal Biochem 107:220-239

31. Teicher MH 1982 Ligand compiled. Med 58, Biomedical Computing Technology Information Center, Nashville, TN

32. Waldman SA, O'Hanley PD, Falkow S, Schoolnik G, Murad F 1984 A simple, sensitive and specific assay for the heat-stable enterotoxin of Escherichia coli. J Infect Dis 149:83-89

33. Giannella RA, Luttrell M, Thompson M 1985 Receptor occupancy and intestinal secretion induced by $E$. coli heat-stable enterotoxin. Gastroenterology 88:1329(abstr) 